\title{
Acute peritoneal dialysis is an efficient and reliable alternative therapy in preterm neonates with acute kidney injury
}

\author{
Yan Xing ${ }^{1 \#}$, Kai Sheng ${ }^{2 \#}$, Hui Liu ${ }^{1 \#}$, Song $\mathrm{Wu}^{3}$, Hongling Wei ${ }^{1}$, Rui $\mathrm{Li}^{1}$, Jing Wang ${ }^{1}$, Zailing $\mathrm{Li}^{1}$, \\ Xiaomei Tong ${ }^{1}$ \\ ${ }^{1}$ Department of Pediatrics, Peking University Third Hospital, Beijing, China; ${ }^{2}$ Department of emergency, Beijing Children's Hospital, Capital \\ Medical University, Beijing, China; ${ }^{3}$ Department of Cardiac Surgery, Peking University Third Hospital, Beijing, China \\ Contributions: (I) Conception and design: Y Xing, K Sheng, Z Li, X Tong; (II) Administrative support: Y Xing, K Sheng, X Tong; (III) Provision of \\ study materials or patients: All authors; (IV) Collection and assembly of data: Y Xing, K Sheng, H Liu, H Wei; (V) Data analysis and interpretation: \\ Y Xing, K Sheng, H Liu; (VI) Manuscript writing: All authors; (VII) Final approval of manuscript: All authors. \\ \#These authors contributed equally to this work. \\ Correspondence to: Xiaomei Tong; Zailing Li. Department of Pediatrics, Peking University Third Hospital, Beijing 100191, China. \\ Email: tongxm2007@126.com; topbj163@sina.com.
}

\begin{abstract}
Background: This study aimed to assess the underlying causes and outcomes of acute peritoneal dialysis (APD) and the complications of PD procedure in preterm neonates with acute kidney injury (AKI).

Methods: A retrospective study of 21 preterm neonates who underwent APD in a neonatal intensive care unit (NICU) in Peking University Third Hospital between 2016 and 2019 was conducted. The demographic, clinical, biochemistry, and PD procedure-related information of the neonates was analyzed.

Results: Of the 21 preterm neonates, the average gestational age (GA) was $28.9 \pm 2.6$ weeks, and the average birth weight was $1,226.7 \pm 495.3 \mathrm{~g}$, and included 5 (23.8\%) low-birth-weight infants (LBWIs), 7 (33.3\%) very LBWIs (VLBWIs), and 9 (42.9\%) extremely LBWIs (ELBWIs). The major underlying causes for APD were asphyxia $(66.7 \%, \mathrm{n}=14)$ and twin-twin transfusion syndrome $(47.6 \%, \mathrm{n}=10)$. PD procedure-related complications mainly involved inadequate drainage $(n=5,23.8 \%)$ and drainage infections $(n=2,9.5 \%)$. The median duration of PD was 3 days (range, 1 hour-20 days). Compared to pre-PD, blood urea nitrogen (BUN) and serum $\mathrm{K}^{+}$levels were significantly decreased post-PD $(\mathrm{P}<0.05)$. After $\mathrm{PD}$, edema disappeared in $77.8 \%$ $(n=14 / 18)$ of patients, and $42.9 \%$ patients $(n=9 / 21)$ gained normal urine output. Although 8 of the $21(38.1 \%)$ patients died and 6 (29.6\%) abandoned therapy, 7 (33.3\%) patients including 1 VLBWI and 3 ELBWI survived.

Conclusions: APD is an efficient and reliable alternative route of renal replacement therapy particularly for reducing BUN and $\mathrm{K}^{+}$levels in preterm neonates with AKI. APD is practicable in critically ill preterm neonates, even in LBWIs and ELBWIs.
\end{abstract}

Keywords: Acute kidney injury (AKI); acute peritoneal dialysis (APD); preterm neonates

Submitted Nov 24, 2020. Accepted for publication Feb 03, 2021.

doi: $10.21037 /$ tp-20-469

View this article at: http://dx.doi.org/10.21037/tp-20-469

\section{Introduction}

Despite consistent improvement in care of critically ill neonates, acute kidney injury (AKI) still has an incidence rate of $6-8 \%$ in neonatal intensive care units (NICUs), especially in low-birth-weight infants (LBWIs), including very LBWI (VLBWIs), and extremely LBWI (ELBWIs) (1-3). Neonates with AKI have a mortality rate of $45 \%$, and renal failure accounts for $7 \%$ of all deaths in NICUs $(4,5)$. Therefore, AKI is an independent predictor of mortality and also the leading indication of acute dialysis in NICUs (5). 
Over the years, acute peritoneal dialysis (APD) has been successfully adopted for critically ill neonates since it has a few key advantages over hemodialysis, such as significantly lower cost, relatively easier application, and simpler technique (4). The process of PD uses the peritoneum as a membrane across which fluids and dissolved substances such as electrolytes, urea, creatinine, glucose, osmotically active particles, and other small molecules are exchanged from the blood (6). With the advances in care for neonates in NICUs, the percentage of newborns requiring acute APD has been gradually increased (4). However, the experience in APD for newborn patients, particularly in preterm neonates, is still relatively immature. Therefore, the aim of the present study was to evaluate the indications, complications, and outcomes of APD in preterm neonates at a referral university hospital.

We present the following article in accordance with the STROBE reporting checklist (available at http://dx.doi. org/10.21037/tp-20-469).

\section{Methods}

\section{Subjects}

The data of 21 preterm neonates with a gestational age (GA) $<37$ weeks who were diagnosed with AKI and underwent APD between January 1, 2017 and December 31, 2019 in the NICU at the Peking University Third Hospital (Beijing, China) were retrospectively analyzed. The study was conducted in accordance with the Declaration of Helsinki (as revised in 2013). The study was been approved by the Medical Ethics Committee of Peking University Third Hospital (no. IRB00006761-M2019475). Individual consent for this retrospective analysis was waived. AKI was diagnosed according to the following criteria from the Kidney Diseases: Improving Global Outcome (KDIGO) guidelines: serum creatinine $(\mathrm{sCr})$ increases from baseline $\geq 0.3 \mathrm{mg} / \mathrm{dL}(26.5 \mu \mathrm{mol} / \mathrm{L})$ within 48 hours or greater than 1.5 times the lowest previous value, and urine output $<0.5 \mathrm{~mL} / \mathrm{kg} / \mathrm{h}$ for 6 hours (7). Daily urine was collected and measured in a bag by catheterization of the bladder, or urine output was calculated by measuring the diaper weight. The demographic, clinical, and laboratory data including $\mathrm{sCr}$, blood urea nitrogen (BUN), and serum potassium $\left(\mathrm{K}^{+}\right)$were collected. The $\mathrm{PD}$ procedure, related complications, efficacy, and outcome were also evaluated.

\section{PD procedure}

PD was decided upon by the attending neonatologist and pediatric nephrologist. All the parents of the neonates were informed of the rationale behind PD treatment before the procedure. The PD catheter placement was performed under local anesthesia by pediatric surgeons with extensive experience in PD procedures in small neonates. All procedures were carried out under strict aseptic conditions. In our patients, 4 abdomen positions were used as the catheter insertion sites: the umbilicus, $0.5-1 \mathrm{~cm}$ left of the umbilicus, $0.5-1 \mathrm{~cm}$ right of the umbilicus, and left of McBurney's point. Because a neonatal PD catheter (Tenckhoff, 2 cuffs) was unavailable before January 2017 in our NICU, the following 4 different types of catheters were used in our patients: a 14-gauge gastric tube (T1), a 10-gauge aseptic inhale phlegm pipe (T2), neonatal PD catheter (T3), and 12-gauge urethral catheter (T4). Several extra side holes at the terminal of catheter were cut before insertion in order to maintain unobstructed drainage. The tip of the catheter was placed in the Douglas pouch. After the guide was removed, $50 \mathrm{~mL}$ of heparinized saline was infused rapidly, and its outflow was assessed to confirm adequate function. The catheter was circularly sutured and taped flat to the skin.

The catheter was connected to a syringe holding dialysis fluid and to a urine collection bag through the $\mathrm{Y}$ and $\mathrm{T}$ connectors, respectively. PD was started with a dwell volume of $10-20 \mathrm{~mL} / \mathrm{kg}$. PD fluids were prewarmed to $37.2{ }^{\circ} \mathrm{C}$. After the dwell, the PD fluid was drained into a urine-collecting device allowing exact determination of the drained volume.

The dialysate solutions that we used were standard PD solution (Baxter International Inc., China), in which heparin (100 U/L of dialysate), potassium chloride (2-4 mmol/L of dialysates), and insulin could be added depending on the patient's potassium and glucose level. Antibiotics could also be included in dialysates, including sulperazone (loading dose $500 \mathrm{mg} / \mathrm{L}$, maintenance dose $52.5-125 \mathrm{mg} / \mathrm{L}$ ), ceftazidime (loading dose $500 \mathrm{mg} / \mathrm{L}$, maintenance dose $125 \mathrm{mg} / \mathrm{L}$ ), and vancomycin (loading dose $30 \mathrm{mg} / \mathrm{L}$, maintenance dose $1.5 \mathrm{mg} / \mathrm{kg} / \mathrm{L}$ ). The glucose concentration varied from $1.5 \%$ to $4.25 \%$, depending on the presence of hypervolemia and edema. Standard initial prescription consisted of 5 minutes for installation of fluid and 40-50 minutes dwell time followed by 15 minutes of 
Table 1 General information of the 21 acute peritoneal dialysis patients

\begin{tabular}{|c|c|}
\hline Parameter & $P D(n=21)$ \\
\hline BW (g) & $1,226.7 \pm 495.3$ \\
\hline GA (week) & $28.9 \pm 2.6$ \\
\hline Male/female (\%) & $12(57.1) / 9(42.9)$ \\
\hline BUN when AKI (mg/dL) & $15.88 \pm 6.48$ \\
\hline sCr when AKI ( $\mu \mathrm{mol} / \mathrm{L})$ & $257.38 \pm 140.35$ \\
\hline $\mathrm{K}$ when $\mathrm{AKI}$ (mmol/L) & $6.55 \pm 1.66$ \\
\hline \multicolumn{2}{|l|}{ BW classification } \\
\hline LBW (\%) & $5(23.8)$ \\
\hline VLBW (\%) & 7 (33.3) \\
\hline ELBW (\%) & $9(42.9)$ \\
\hline Fetal distress (\%) & $1(4.8)$ \\
\hline Asphyxia (\%) & $14(66.7)$ \\
\hline TTS (\%) & $10(47.6)$ \\
\hline Septicemia (\%) & $6(28.6)$ \\
\hline \multicolumn{2}{|l|}{ AKI reason } \\
\hline Prerenal AKI (\%) & $12(57.1)$ \\
\hline Renal AKI (\%) & $9(42.9)$ \\
\hline Arrhythmia (\%) & $8(38.1)$ \\
\hline Edema (\%) & $18(85.7)$ \\
\hline
\end{tabular}

BW, birth weight; LBW, low-birth-weight; VLBW, very low-birthweight; ELBW, extremely low-birth-weight; GA, gestational age; $\mathrm{AKI}$, acute kidney injury; sCr, serum creatinine; $\mathrm{BUN}$, blood urine nitrogen; TTTS, twin-twin transfusion syndrome.

drainage. If adequate dialysis was needed, the dwell volume was gradually increased and the cycles were individualized. Indications for discontinuation of PD treatment included a return to a sufficient urine output $>1 \mathrm{~mL} / \mathrm{kg} / \mathrm{h}$.

\section{Statistical analysis}

The categorical data were compared with the $\chi^{2}$-test. Student's $t$-test was used to test the equality of means of sCr, BUN, and serum $\mathrm{K}^{+}$between pre- and post-dialysis. Time needed for $\mathrm{BUN}, \mathrm{sCr}$ and $\mathrm{K}^{+}$levels to decrease to their lowest level after PD was also compared. A P value $\leq 0.05$ was considered to indicate statistical significance.

\section{Results}

\section{General information of AKI patients}

The general information of the 21 preterm neonates, including 12 boys and 9 girls, who underwent APD for AKI is summarized in Table 1. The median age when AKI was diagnosed was 4 days (range, 2-23 days). The mean GA was $28.9 \pm 2.6$ weeks (range, $25.5-34.2$ weeks). The mean body weight (BW) was $1,226.7 \pm 495.3 \mathrm{~g}$, with the lowest $\mathrm{BW}$ of $540 \mathrm{~g}$. Of the 21 neonates, there were 5 (23.8\%) LBWIs, 7 (33.3\%) VLBWIs, and 9 (42.9\%) ELBWIs.

The mean of $\mathrm{sCr}, \mathrm{BUN}$, and serum $\mathrm{K}^{+}$levels were $257.38 \pm 140.35 \mu \mathrm{mol} / \mathrm{L}, 15.88 \pm 6.48 \mathrm{mg} / \mathrm{dL}$, and $6.55 \pm 1.66 \mathrm{mmol} / \mathrm{L}$, respectively. Of the causes of AKI, $57.1 \%$ of cases $(\mathrm{n}=12)$ were caused by prerenal factors, and $42.9 \%(n=9)$ by renal factors. For the underlying causes of APD, the percentages of cases caused by perinatal asphyxia, twin-twin transfusion syndrome (TTTS), arrhythmia, sepsis, and edema were $66.7 \%(\mathrm{n}=14), 47.6 \%(\mathrm{n}=10), 38.1 \%$ $(\mathrm{n}=8), 28.6 \%(\mathrm{n}=6)$, and $85.7 \%(\mathrm{n}=18)$, respectively.

\section{PD procedure evaluation}

In the present study, 4 different incision positions were used for PD: $28.6 \%(n=6)$ at the umbilicus, $52.4 \%(n=11)$ at $1 \mathrm{~cm}$ to the left of the umbilicus, $14.3 \%(\mathrm{n}=3)$ at $1 \mathrm{~cm}$ to the right of the umbilicus, and $4.7 \%(\mathrm{n}=1)$ to the left of McBurney's point. Notably, 4 different PD tubes were used: $28.6 \%(\mathrm{n}=6)$ with $14 \mathrm{~F}$ gastric tube, $14.3 \%(\mathrm{n}=3)$ with $10 \mathrm{~F}$ suction tube, $52.4 \%(\mathrm{n}=11)$ with neonatal $\mathrm{PD}$ catheter, and $4.7 \%(\mathrm{n}=1)$ with $12 \mathrm{~F}$ catheter. Glucose concentration in PD fluids depended on the patient's plasma glucose level and the results of dialysis. Of our patients, 11 (52.4\%) were given $2.5 \%$ glucose, while the remaining patients were also given $1.5 \%$ and/or $4.25 \%$ glucose. Antibiotics, including ceftazidime, meropenem, cefoperazone-sulbactam and vancomycin, were used in the PD fluids of 9 (42.9\%) patients. The median duration of PD was 3 days (range 1 hour-20 days). The characteristics of the PD procedure are shown in Table S1.

\section{Complications, efficacy and outcomes of APD}

Alterations of BUN, sCr, and serum $\mathrm{K}^{+}$following APD in the 21 patients are shown in Table S2. Post$\mathrm{PD}$ BUN and serum $\mathrm{K}^{+}$were significantly decreased 
A

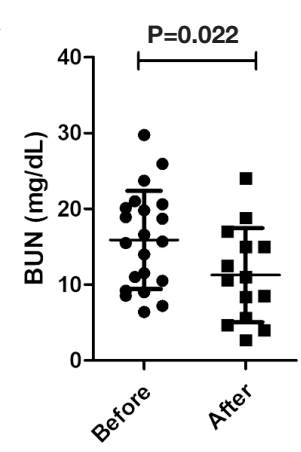

C

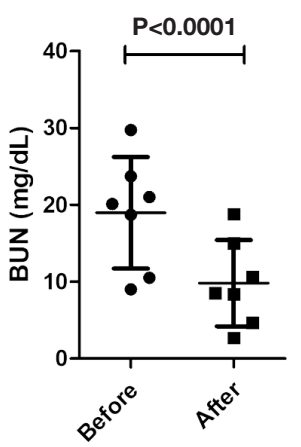

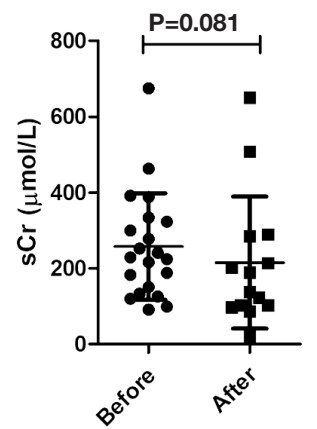
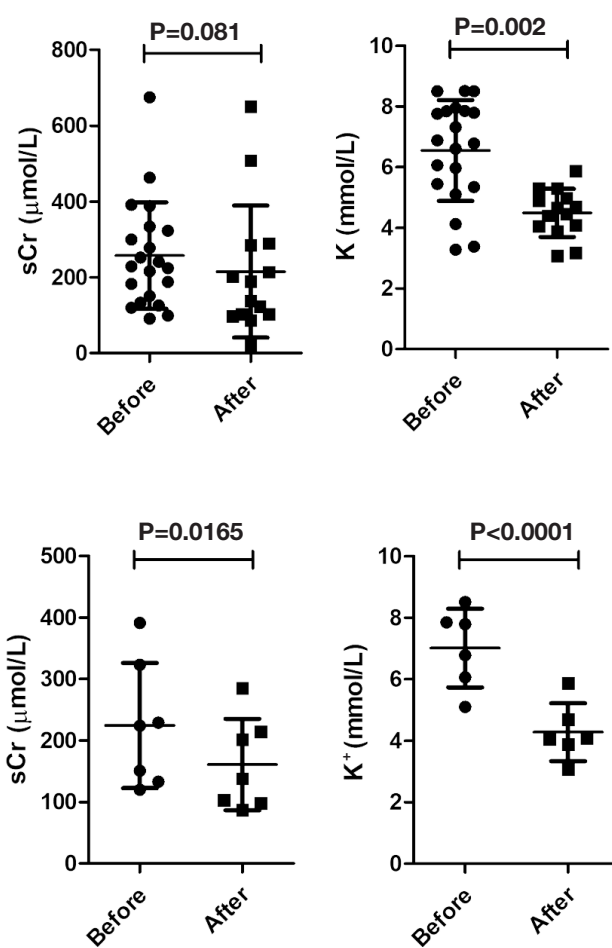

B

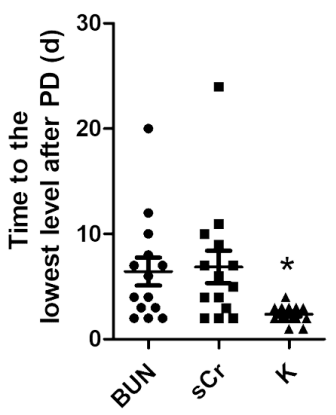

Figure 1 Renal labs were improved following peritoneal dialysis in preterm neonates with acute kidney injury. Preterm neonates with acute kidney injury were treated with peritoneal dialysis (PD). (A) The levels of $\mathrm{BUN}$, serum creatinine (sCr), and serum $\mathrm{K}^{+}$were measured and compared pre- and post-PD. Data are presented with mean \pm SD n=21 (pre-PD) and 14 (post-PD). (B) Comparison of time needed for BUN, sCr and $\mathrm{K}^{+}$levels to decrease to their lowest level after PD. Data are presented with mean $\pm \mathrm{SD} n=14 .{ }^{*} \mathrm{P}<0.05$ vs. BUN and sCr. (C) The levels of BUN, sCr, and $\mathrm{K}^{+}$decreased significantly following $\mathrm{PD}$ in the 7 survivors. Data are presented with mean $\pm \mathrm{SD} \mathrm{n}=7$.

(BUN: $11.27 \pm 6.19$ vs. $15.88 \pm 6.48 \mathrm{mg} / \mathrm{dL}, \mathrm{P}=0.022 ; \mathrm{K}^{+}$: $4.49 \pm 0.79$ vs. $6.55 \pm 1.66 \mathrm{mmol} / \mathrm{L}, \mathrm{P}=0.002)$ compared to pre-PD. After $\mathrm{PD}$, a trend towards a lower $\mathrm{sCr}$ $(215.10 \pm 174.01 \mu \mathrm{mol} / \mathrm{L}$ vs. $257.38 \pm 140.35 \mu \mathrm{mol} / \mathrm{L}$, $\mathrm{P}=0.081$ ) was found (Figure $1 A$ ). After $\mathrm{PD}$, the time for reaching the lowest level of $\mathrm{K}^{+}$was significantly shorter $(2.34 \pm 0.84$ vs. $6.43 \pm 5.06 \mathrm{~d}$ and $6.85 \pm 5.76 \mathrm{~d}, \mathrm{P}=0.035)$ than that of BUN and $\mathrm{sCr}$ (Figure 1B).

The procedural complications, efficacy, and outcomes of PD are shown in Table S1. For complications, 14 cases (66.7\%) did not have PD-related complications, 5 (23.8\%) had poor or inadequate drainage, and $2(9.5 \%)$ had drainage infections. After PD, the median time for the first urination was 1.25 days (range, 12 hours- -9 days), and the median time for reaching normal urine output was 3 days (range, 1-19 days). For the urine amount, 8 cases (38.1\%) still did not produce urine after PD, $4(19.0 \%)$ had a small amount of urine, and $9(42.9 \%)$ showed normal urine output. Although 18 (85.7\%) patients had edema before PD, in 14
(77.8\%) patients, edema disappeared after PD.

Of the 21 patients, $8(38.1 \%)$ died, 6 (28.6\%) abandoned treatment, and $7(33.3 \%)$ survived after PD. Notably, the 7 survivors included 1 VLBWI and 3 ELBWIs. We also compared the alterations of $\mathrm{BUN}, \mathrm{sCr}$, and $\mathrm{K}^{+}$ levels following PD in the 7 survivors, which revealed a significant reduction of the 3 parameters (BUN: 9.81 \pm 5.61 vs. $18.96 \pm 7.24 \mathrm{mg} / \mathrm{dL}, \mathrm{P}<0.0001$; $\mathrm{sCr}: 161.01 \pm 74.39$ vs. $224.42 \pm 101.82 \mu \mathrm{mol} / \mathrm{L}, \mathrm{P}=0.0165 ; \mathrm{K}^{+}$: $4.28 \pm 0.94$ vs. $7.02 \pm 1.28 \mathrm{mmol} / \mathrm{L}, \mathrm{P}<0.0001$ ) (Figure 1 C).

\section{Discussion}

In this present study, a total of 21 preterm neonates were diagnosed as AKI and underwent APD, including 5 LBWIs, 7 VLBWIs, and 9 ELBWIs. Our data show that APD is an effective and reliable alternative therapy in preterm neonates with AKI especially for the correction of BUN level, serum $\mathrm{K}^{+}$level, and edema. 
It has been reported that the most common indication for APD in newborns is oliguric AKI $(8,9)$. In this study, the major indication of APD was AKI, presenting with elevated $\mathrm{BUN}$ and $\mathrm{sCr}$, and $<0.5 \mathrm{~mL} / \mathrm{kg} / \mathrm{h}$ of urine amount. In $57.1 \%$ patients, AKI was caused by the prerenal factors, while renal factors were responsible for the other $42.9 \%$. Of note, dialysis either PD or HD could be avoided through appropriate treatment for AKI caused by pre renal factors. Additionally, the underlying causes in the 21 preterm neonates were perinatal asphyxia (66.7\%), TTTS (47.6\%), arrhythmia (38.1\%), and sepsis (28.6\%), indicating that perinatal asphyxia is the major underlying cause for AKI in preterm neonates. It was previously reported that the majority of underlying causes for neonates who accepted APD treatment are perinatal asphyxia, metabolic disease, and sepsis, and that APD is effective in treating certain metabolic disorders and AKI in newborns (9-11). The patients who had respiratory distress syndrome, patent ductus arteriosus, coarctation of the aorta, truncus arteriosus, total anomalous pulmonary venous return, posterior urethral valve, and nephronophthisis are also potential candidates for APD (10).

PD is an invasive, relatively easy, and technically simple procedure in comparison with hemodialysis (8-12). In this study, especially in VLBWIs and ELBWIs, APD was appropriately performed, and serious complications associated with dialyses were not observed in the majority of patients $(66.7 \%)$. PD has comparable risks such as high rates of technical complications and mortality in small neonates, likely related to the lack of size-specific equipment for these patients (13). It was reported that the primary complication of $\mathrm{PD}$ is infection due to the presence of a permanent tube in the abdomen (9). To prevent infections in our study, 9 (42.9\%) patients were preventively given antibiotics in PD fluids. Infections presenting with drainage infection only occurred in $2(9.5 \%)$ patients, and poor or inadequate drainage occurred in $5(23.8 \%)$ patients. One study of an 8-year experience of APD in neonates reported that the most common complications of PD were hyperglycemia, fluid leakage, and peritonitis (9). Another study reported peritonitis and leakage in 16 VLBWIs who underwent APD (12). Fluid leakage and obvious peritonitis were not observed in our patients. The results of this study suggest that in the future practice of $\mathrm{PD}$, prophylactic use of antibiotics may not be required; but if it is needed, the antibiotics used in the PD fluid should be selected as far as possible to minimize or avoid the damage to the kidney. Frequent hyperglycemia has been reported in PD neonates, likely due to glucose intolerance of neonates with VLBW, or by serious underlying disease (9). Dialysate solutions with $1.5 \%, 2.5 \%$, or $4.25 \%$ glucose concentrations were used in the current study. The selection of glucose concentration would depend on serum glucose levels and the fluid balance of the patient (14). Although hyperglycemia did not occur during PD in our patients, we still emphasize that appropriate dialysate output and dwell-time, monitoring fluid, glucose, and electrolyte balance are essentials of the PD especially in neonates.

In the premature neonates, the length of the straight dialysis catheter may increase the risk of bowel perforation. The pigtail dialysis catheter is less likely to erode the bowel and is now being used more frequently in neonates (14). In our patients, different abdomen positions and varying catheter types were used as reported in various sources (9-12,15-17). Catheter-related complications such as catheter leak, poor drainage, and kinking should be carefully monitored (18). In this study, the 14-gauge gastric tube was used in 6 patients $(28.6 \%)$, and only 1 showed drainage infection, with 3 (50\%) surviving. This indicates that the 14-gauge gastric tube is safe and effective, and may be a better catheter for PD than the other 3 types. Use of a 14-gauge vascular catheter for APD access in 16 VLBWIs was also reported: PD demonstrated successful control of hyperkalemia, fluid overload, and metabolic acidosis, and 10 patients survived and had full recovery of their renal function (14). In our study, a neonatal PD catheter was sued in $11(52.4 \%)$ patients, with $4(36.4 \%)$ of them surviving. Our results suggest that a variety of catheters and abdomen positions could be used for PD even in preterm neonates, and this may depend on the catheter availability and abdomen conditions. In other words, when there is no dialysis tube of the appropriate size in such patients with too small body weight and gestational age, some alternative catheters can be selected according to the weight of the child and clinical practice. Moreover, the individualized PD in particular for LBWI and VLBWI should be determined according to the amount of fluid removal, abdominal distension degree, electrolyte status, urine output and the overall clinical situation.

After PD, BUN and serum $\mathrm{K}^{+}$levels were decreased significantly, while the sCr level did not alter remarkably in our patients. One study reported a percentage reduction in BUN in neonates of $23.7 \%$ at $24 \mathrm{~h}$ following $\mathrm{PD}$ treatment (19). In an ELBWI with AKI, reductions of $59.4 \%$ from 69 to $28 \mathrm{mg} / \mathrm{dL}$ in BUN and of $61 \%$ from 203.3 to $79.56 \mu \mathrm{mol} / \mathrm{L}$ in $\mathrm{sCr}$ were reportedly obtained 
following $\mathrm{PD}$ (18). In this study, we also compared the time needed for BUN, sCr, and $\mathrm{K}^{+}$levels to decrease to their lowest level after PD. We found that the serum $\mathrm{K}^{+}$level decreased very rapidly around at 2.34 days after PD. In our patients, 18 (85.7\%) had edema before PD, whereas edema in $14(77.8 \%)$ patients had obviously disappeared after PD. These data suggest that PD is effective in correcting BUN level, serum $\mathrm{K}^{+}$level, and edema. The reason for slow clearance of creatinine is not yet clear. Therefore, it needs to be further studied how to increase the clearance rate of creatinine in PD.

There is limited data regarding the mortality of newborn neonates who undergo PD. Mortality may be likely related to underlying medical conditions in PD patients. The mortality rate has been reported to reach $95 \%$ when AKI and multiple organ dysfunction occur together $(9,20)$. Two case series using PD in neonates each reported $>50 \%$ mortality but included many neonates with inborn defects in metabolism $(10,15)$. A retrospective study of $10 \mathrm{VLBW}$ neonates with AKI who accepted PD treatment reported an overall mortality of $80 \%$ (21). In our preterm neonates with $\mathrm{PD}$, the rates of death $(\mathrm{n}=8)$ and survival $(\mathrm{n}=7)$ were $38.1 \%$ and $33.3 \%$, respectively. Notably, 1 VLBWI and 3 ELBWI survived following APD treatment in our patients. It was previously reported that $\mathrm{PD}$ was successfully implemented using a standard, commercially available PD catheter in an 830-g premature infant with oligo-anuric AKI and deteriorating respiratory status (18). Our data also showed that the levels of $\mathrm{BUN}, \mathrm{sCr}$, and $\mathrm{K}^{+}$were significantly decreased following APD in the 7 survivors. These suggest that APD is feasible and also effective in preterm and/or premature neonates even in the VLBWIs and ELBWIs.

Compared with hemodialysis, PD has less impact on systemic hemodynamics, and requires relatively simple equipment and technology for operation, which is easy to implement and convenient for clinical practice. For VLBWI, it is difficult to have suitable hemodialysis tubing and equipment. But it should be noted that the effect of PD may not be as efficient as hemodialysis.

Taken together, our data show that renal recovery following APD is possible in preterm neonates with severe oligo-anuric AKI. The smallest of patients are at high risk for PD-related complications and mortality. However, this study was based on data from a single center, and the number patients was small. Some patients were discharged after recovery of renal function, and long-term follow-up was not performed. Further studies and/or more registry data are needed to accumulate a larger bank of experience with APD in newborn patients, particularly in preterm neonates. We nevertheless emphasize considering the initiation of $\mathrm{PD}$ treatment in all preterm neonates, and that technical adaptation and improvement is required for the $\mathrm{PD}$ procedure in preterm neonates, especially in VLBWIs and ELBWIs.

\section{Acknowledgments}

Funding: This work was supported by the Beijing Natural Science Foundation (no. S170003 to YX and no. S160004 to XT) and Peking University Third Hospital Research Fund for outstanding overseas returnees (No. BYSYLXHG2019005 to YX) and Peking University Medical cross research seed fund (Medical-X, No. BMU2020MX010).

\section{Footnote}

Reporting Checklist: The authors have completed the STROBE reporting checklist. Available at http://dx.doi. org/10.21037/tp-20-469

Data Sharing Statement: Available at http://dx.doi. org/10.21037/tp-20-469

Conflicts of Interest: All authors have completed the ICMJE uniform disclosure form (available at http://dx.doi. org/10.21037/tp-20-469). The authors have no conflicts of interest to declare.

Ethical Statement: The authors are accountable for all aspects of the work in ensuring that questions related to the accuracy or integrity of any part of the work are appropriately investigated and resolved. The study was conducted in accordance with the Declaration of Helsinki (as revised in 2013). The study was approved by the ethics committee of our center (no. IRB00006761-M2019475). Individual consent for this retrospective analysis was waived.

Open Access Statement: This is an Open Access article distributed in accordance with the Creative Commons Attribution-NonCommercial-NoDerivs 4.0 International License (CC BY-NC-ND 4.0), which permits the noncommercial replication and distribution of the article with the strict proviso that no changes or edits are made and the original work is properly cited (including links to both the formal publication through the relevant DOI and the license). 
See: https://creativecommons.org/licenses/by-nc-nd/4.0/.

\section{References}

1. Goldstein SL, Somers MJ, Baum MA, et al. Pediatric patients with multi-organ dysfunction syndrome receiving continuous renal replacement therapy. Kidney Int 2005;67:653-8.

2. Gong WK, Tan TH, Foong PP, et al. Eighteen years experience in pediatric acute dialysis: analysis of predictors of outcome. Pediatr Nephrol 2001;16:212-5.

3. Spector BL, Misurac JM. Renal Replacement Therapy in Neonates. Neoreviews 2019;20:e697-710.

4. Lee MM, Chua AN, Yorgin PD. Neonatal peritoneal dialysis. NeoReviews 2005;6:e384-91.

5. Jetton JG, Askenazi DJ. Acute kidney injury in the neonate. Clin Perinatol 2014;41:487-502.

6. Gokal R, Mallick NP. Peritoneal dialysis. Lancet. 1999;353:823-8.

7. Ostermann M. Diagnosis of acute kidney injury: Kidney Disease Improving Global Outcomes criteria and beyond. Curr Opin Crit Care 2014;20:581-7.

8. Hakan N, Aydin M, Zenciroglu A, et al. Acute peritoneal dialysis in the newborn period: a 7-year single-center experience at tertiary neonatal intensive care unit in Turkey. Am J Perinatol 2014;31:335-8.

9. Kara A, Gurgoze MK, Aydin M, et al. Acute peritoneal dialysis in neonatal intensive care unit: An 8-year experience of a referral hospital. Pediatr Neonatol 2018;59:375-9.

10. Alparslan C, Yavascan O, Bal A, et al. The performance of acute peritoneal dialysis treatment in neonatal period. Ren Fail 2012;34:1015-20.

11. Matthews DE, West KW, Rescorla FJ, et al. Peritoneal

Cite this article as: Xing $\mathrm{Y}$, Sheng $\mathrm{K}$, Liu $\mathrm{H}, \mathrm{Wu} \mathrm{S}$, Wei H, Li R, Wang J, Li Z, Tong X. Acute peritoneal dialysis is an efficient and reliable alternative therapy in preterm neonates with acute kidney injury. Transl Pediatr 2021;10(4):893-899. doi: $10.21037 /$ tp-20-469 dialysis in the first 60 days of life. J Pediatr Surg 1990;25:110-5; discussion 116.

12. Yu JE, Parl MS, Pai KS. Acute peritoneal dialysis in very low birth weight neonates using vascular catheter. Pediatr Nephrol 2010;25:367-71.

13. LaPlant MB, Saltzman DA, Segura BJ, et al. Peritoneal dialysis catheter placement, outcomes and complications. Pediatr Surg Int 2018;34:1239-44.

14. Schröder CH. New peritoneal dialysis fluids: practical use for children. Pediatr Nephrol 2003;18:1085-8.

15. Unal S, Bilgin L, Gunduz M, et al. The implementation of neonatal peritoneal dialysis in a clinical setting. J Matern Fetal Neonatal Med 2012;25:2111-4.

16. Oyachi N, Obana K, Kimura S, et al. Use of a flexible Blake ${ }^{\circledR}$ silicone drains for peritoneal dialysis in the neonatal intensive care unit. Pediatr Int 2011;53:417-8.

17. Stojanovic V, Bukarica S, Doronjski A, et al. Peritoneal dialysis in neonates with extremely low body weight at birth: new modality of using IV cannula for peritoneal access. Iran J Pediatr 2013;23:718-20.

18. Harshman LA, Muff-Luett M, Neuberger ML, et al. Peritoneal dialysis in an extremely low-birth-weight infant with acute kidney injury. Clin Kidney J 2014;7:582-5.

19. Diane Mok TY, Tseng MH, Chiang MC, et al. Renal replacement therapy in the neonatal intensive care unit. Pediatr Neonatol 2018;59:474-80.

20. Stojanović VD, Bukarica SS, Antić JB, et al. Peritoneal Dialysis in Very Low Birth Weight Neonates. Perit Dial Int 2017;37:389-96.

21. Tetta C, Bellomo R, Ronco C. Artificial organ treatment for multiple organ failure, acute renal failure, and sepsis: recent new trends. Artif Organs 2003;27:202-13.

(English Language Editor: J. Gray) 
Supplementary

Table S1 Characteristics of procedure, efficacy, complications, and outcomes of the 21 acute peritoneal dialysis patients

\begin{tabular}{|c|c|c|c|c|c|c|c|c|c|c|c|c|c|c|c|}
\hline Patients & BW (g) & GA (weeks) & $\mathrm{Age}^{\mathrm{a}}$ (days) & Position $^{b}$ & Glucose $^{c}$ & Antibiotics $^{d}$ & Canula $^{\circ}$ & Duration ${ }^{f}$ & Edema $1^{9}$ & Edema $2^{\mathrm{h}}$ & Time $1^{i}$ & Time $2^{\mathrm{j}}$ & Urine output ${ }^{k}$ & Complications' & Out-comes \\
\hline 1 & 1,540 & 31 & 2 & B & 2.5 & & T2 & $12 \mathrm{~h}$ & - & - & - & - & Anuria & No & Death \\
\hline 2 & 800 & 27.71 & 9 & A & 2.5 & & $\mathrm{~T} 1$ & $48 \mathrm{~h}$ & Yes & No & - & - & Anuria & No & Death \\
\hline 3 & 1,100 & 28.43 & 5 & D & $1.5 ; 2.5 ; 4.25$ & $\begin{array}{l}\text { Ceftazidime; } \\
\text { Vancomycin }\end{array}$ & $\mathrm{T} 1$ & $8 d$ & Yes & No & $12 \mathrm{~h}$ & - & Small & No & Abandoned \\
\hline 4 & 830 & 26.14 & 23 & B & $2.5 ; 4.25$ & $\begin{array}{l}\text { Cefoperazone } \\
\text { sulbactam }\end{array}$ & T2 & $10 \mathrm{~d}$ & Yes & No & - & - & Anuria & $\begin{array}{l}\text { Inadequate } \\
\text { drainage }\end{array}$ & Abandoned \\
\hline 5 & 1,040 & 28 & 2 & B & 2.5 & & T4 & $5 d$ & Yes & Yes & $36 \mathrm{~h}$ & $48 \mathrm{~h}$ & Small & No & Abandoned \\
\hline 6 & 900 & 25.71 & 4 & C & 2.5 & $\begin{array}{l}\text { Cefoperazone- } \\
\text { sulbactam }\end{array}$ & $\mathrm{T} 1$ & $48 \mathrm{~h}$ & Yes & No & - & - & Anuria & No & Death \\
\hline 7 & 2,280 & 33.57 & 3 & B & 2.5 & & $\mathrm{~T} 2$ & $4 \mathrm{~h}$ & Yes & - & - & - & Anuria & $\begin{array}{l}\text { Inadequate } \\
\text { drainage }\end{array}$ & Death \\
\hline 8 & 540 & 26.14 & 6 & c & $1.5 ; 2.5 ; 4.25$ & Ceftazidime & $\mathrm{T} 1$ & $20 \mathrm{~d}$ & Yes & No & $9 d$ & $19 d$ & Normal & $\begin{array}{l}\text { Drainage } \\
\text { infection }\end{array}$ & Survival \\
\hline 9 & 1,510 & 30.14 & 10 & C & $1.5 ; 2.5$ & & $\mathrm{~T} 1$ & $12 d$ & No & No & $12 \mathrm{~h}$ & $5 d$ & Normal & No & Survival \\
\hline 10 & 1,310 & 30 & 2 & A & $2.5 ; 4.25$ & & $\mathrm{~T} 1$ & $5 d$ & Yes & No & $3 d$ & $4 d$ & Normal & No & Survival \\
\hline 11 & 1,370 & 29.43 & 3 & A & 2.5 & & T3 & $10 \mathrm{~h}$ & Yes & No & - & - & Anuria & No & Death \\
\hline 12 & 1,120 & 30 & 2 & A & $2.5 ; 4.25$ & Ceftazidime & T3 & $10 \mathrm{~d}$ & Yes & No & $24 \mathrm{~h}$ & - & Small & $\begin{array}{l}\text { Inadequate } \\
\text { drainage }\end{array}$ & Abandoned \\
\hline 14 & 800 & 25.5 & 7 & A & $2.5 ; 4.25$ & $\begin{array}{l}\text { Cefoperazone- } \\
\text { sulbactam }\end{array}$ & T3 & $3 d$ & Yes & No & - & $27 \mathrm{~h}$ & Normal & No & Survival \\
\hline 15 & 1,440 & 29.10 & 3 & B & 2.5 & & T3 & $3 d$ & Yes & No & $24 \mathrm{~h}$ & - & Small & No & Abandoned \\
\hline 16 & 940 & 28.30 & 4 & B & 2.5 & & T3 & $5 \mathrm{~h}$ & Yes & No & - & - & Anuria & $\begin{array}{l}\text { Inadequate } \\
\text { drainage }\end{array}$ & Death \\
\hline 17 & 1,480 & 29.30 & 13 & B & 2.5 & & T3 & $3 d$ & No & No & $24 \mathrm{~h}$ & $36 \mathrm{~h}$ & Normal & No & Abandoned \\
\hline 18 & 2,110 & 32.60 & 3 & B & 1.5 & & T3 & $4 \mathrm{~h}$ & Yes & Yes & $2 d$ & $4 d$ & Normal & No & Survival \\
\hline 19 & 790 & 26.00 & 2 & B & 2.5 & Meropenem & T3 & $1 \mathrm{~h}$ & Yes & No & - & - & Normal & No & Death \\
\hline 20 & 2,200 & 34.20 & 2 & B & 1.5 & $\begin{array}{l}\text { Cefoperazone- } \\
\text { sulbactam }\end{array}$ & T3 & $6 d$ & Yes & No & $4 \mathrm{~h}$ & $24 \mathrm{~h}$ & Normal & No & Survival \\
\hline 21 & 790 & 25.50 & 11 & B & 2.5 & & T3 & $2 \mathrm{~h}$ & Yes & No & - & $27 \mathrm{~h}$ & Anuria & $\begin{array}{l}\text { Inadequate } \\
\text { drainage }\end{array}$ & Death \\
\hline
\end{tabular}

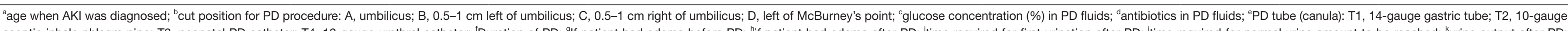

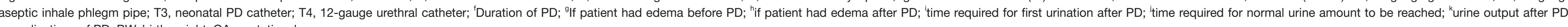
birth weight; GA, gestational age. 
Table S2 Changes in the BUN, sCr, and serum $\mathrm{K}^{+}$levels following acute peritoneal dialysis

\begin{tabular}{|c|c|c|c|c|c|c|c|c|c|}
\hline Patients & $\begin{array}{l}\text { BUN pre-PD } \\
\text { (mg/dL) }\end{array}$ & $\begin{array}{c}\text { Lowest BUN } \\
\text { post-PD (mg/dL) }\end{array}$ & $\begin{array}{c}\text { Time to lowest BUN } \\
\text { post-PD (d) }\end{array}$ & $\begin{array}{l}\text { sCr pre-PD } \\
(\mu \mathrm{mol} / \mathrm{L})\end{array}$ & $\begin{array}{l}\text { Lowest sCr post-PD } \\
\qquad(\mu \mathrm{mol} / \mathrm{L})\end{array}$ & $\begin{array}{l}\text { Time to lowest } \\
\text { sCr post-PD (d) }\end{array}$ & $\begin{array}{l}\text { K pre-PD } \\
(\mathrm{mmol} / \mathrm{L})\end{array}$ & $\begin{array}{l}\text { Lowest K post-PD } \\
\qquad(\mathrm{mmol} / \mathrm{L})\end{array}$ & $\begin{array}{l}\text { Time to lowest } \\
\text { K post-PD (d) }\end{array}$ \\
\hline 1 & 7.20 & - & - & 278.00 & - & - & - & - & - \\
\hline 2 & 14.00 & - & - & 252.00 & - & - & 7.31 & - & - \\
\hline 3 & 18.90 & 4.00 & 7 & 388.00 & 21.00 & 7 & 4.12 & 3.18 & 2 \\
\hline 4 & 11.50 & 5.60 & 2 & 675.00 & 123.00 & 9 & 5.97 & 4.67 & 2 \\
\hline 5 & 19.80 & 17.00 & 4 & 241.00 & 290.00 & 4 & 8.50 & 4.46 & 3 \\
\hline 6 & 20.60 & 11.00 & 2 & 300.00 & 508.00 & 2 & 6.88 & 5.30 & 2 \\
\hline 7 & 15.70 & - & - & 216.00 & - & - & 7.76 & - & - \\
\hline 8 & 23.70 & 15.00 & 12 & 323.00 & 285.00 & 1 & 6.06 & 3.08 & 4 \\
\hline 9 & 21.00 & 8.40 & 2 & 151.00 & 87.00 & 2 & 5.10 & 3.88 & 2 \\
\hline 10 & 9.00 & 2.70 & 4 & 120.00 & 103.00 & 4 & 6.78 & 5.88 & 2 \\
\hline 11 & 9.20 & - & - & 99.00 & - & - & 5.44 & - & - \\
\hline 12 & 15.50 & - & - & 334.00 & - & - & 3.28 & - & - \\
\hline 13 & 20.10 & 8.50 & 8 & 391.00 & 202.00 & 11 & 7.85 & 4.06 & 3 \\
\hline 14 & 29.72 & 18.80 & 1 & 133.00 & 98.00 & 1 & 6.60 & 4.98 & 1 \\
\hline 15 & 8.54 & 12.50 & 3 & 91.00 & 103.00 & 3 & 7.84 & 4.40 & 3 \\
\hline 16 & 6.40 & - & - & 183.00 & - & - & 3.38 & - & - \\
\hline 17 & 16.60 & 15.00 & 2 & 126.00 & 189.00 & 24 & 8.50 & 4.90 & 2 \\
\hline 18 & 10.50 & 4.70 & 3 & 224.00 & 138.00 & 1 & 7.79 & 4.09 & 3 \\
\hline 19 & 11.00 & - & - & 188.00 & - & - & 7.95 & - & - \\
\hline 20 & 18.70 & 10.60 & 2 & 229.00 & 214.00 & 2 & 8.51 & 4.69 & 3 \\
\hline 21 & 25.90 & 24.00 & 1 & 463.00 & 650.00 & 1 & 5.34 & 5.30 & 1 \\
\hline
\end{tabular}

